Gijsen, R., Jochemsen, H., Dijk, L. van, Caspers, P. Frequency of ill-founded off-label prescribing in Dutch general practice. Pharmacoepidemiology and Drug Safety: 2009, 18(1), 8491

\begin{tabular}{|l|l|}
\hline Postprint Version & 1.0 \\
\hline Journal website & $\underline{\text { http://dx.doi.org/doi:10.1002/pds.1689 }}$ \\
\hline Pubmed link & $\underline{\text { http://www.ncbi.nlm.nih.gov/pubmed/19111012 }}$ \\
\hline DOI & $10.1002 /$ pds.1689 \\
\hline
\end{tabular}

This is a NIVEL certified Post Print, more info at http://www.nivel.eu

\title{
Frequency of ill-founded off-label prescribing in Dutch general practice
}

\author{
RONALD GIJSEN MSC ${ }^{1 *}$, z , HADASSA JOCHEMSEN BSC ${ }^{2 \mathrm{x}}$, LISET VAN DIJK PHD ${ }^{4}$ AND \\ PETER CASPERS MSC ${ }^{3 \mathrm{~K}}$ \\ ${ }^{1}$ Department of Public Health Status and Forecasting, National Institute for Public Health and \\ the Environment, Bilthoven, The Netherlands \\ ${ }^{2}$ Centre for the Quality of Chemical-Pharmaceutical Products, National Institute for Public \\ Health and the Environment, Bilthoven, The Netherlands \\ ${ }^{3}$ Centre for the Quality of Chemical-Pharmaceutical Products, National Institute for Public \\ Health and the Environment, Bilthoven, The Netherlands \\ ${ }^{4}$ NIVEL, Netherlands Institute for Health Services Research, Utrecht, The Netherlands
}

SUMMARY

Purpose The aim of this study is to quantify the extent of ill-founded off-label drug prescriptions in Dutch general practice. The study is based upon information on both the prescription itself and the patient's medical history.

Methods In total, 48 combinations of drugs and off-label indications were selected from a list of 477 known off-label combinations. These 48 combinations were considered as ill-founded since pharmacotherapeutic handbooks or clinical practice guidelines did not provide evidence for their efficacy and safety. They were considered to be relevant for investigation in general practice. We used a nationally representative information network of 85 general practices in the Netherlands. By using information on the patients' diagnoses and medication in the period before and after the prescription, we were able to exclude non-conclusively off-label prescriptions.

Results Twenty-one of the selected 48 off-label combinations did not occur in Dutch general practice. The drugs with the highest proportion of ill-founded offlabel prescriptions were betahistine (26.7\%), celecoxib (16.3\%) and etoricoxib (12.5\%). In total, $18.2 \%$ of the prescriptions, which were initially assessed as illfounded off-label, were re-evaluated as on-label, after considering the patient's medical history.

Conclusions Ill-founded off-label prescribing in Dutch general practice is limited for 48 relevant combinations of drugs and off-label indications. In order to overcome limitations in registration databases, it is useful to look at as much information as possible-for example,co-medication and co-morbidity—when determining off-label prescribing. Studying ill-founded off-label prescribing should be performed on a day-to-day basis, especially for recently introduced drugs. 
Gijsen, R., Jochemsen, H., Dijk, L. van, Caspers, P. Frequency of ill-founded off-label prescribing in Dutch general practice. Pharmacoepidemiology and Drug Safety: 2009, 18(1), 84-

\section{INTRODUCTION}

New drugs need to be authorized before market entrance.

To receive authorization, a favourable balance between beneficial and harmful effects has to be demonstrated.

Drugs are usually registered for a limited number of clinical diagnoses (indications) and for adult patients only. However, in daily practice, drugs are often used in situations that do not adhere to the authorization requirements. Such 'off-label prescribing' refers to the use of a drug that is not in line with the terms as formulated in the summary of product characteristics (SPC), that accompanies every registered product. A distinction should be made between well-founded and ill-founded (disputable) off-label prescriptions. In contrast to ill-founded, well-founded off-label prescriptions are recommended in clinical practice guidelines or pharmacotherapeutic handbooks. These recommendations are based on systematic examination of the published literature. The efficacy of ill-founded off-label prescription is often questionable and adverse drug reactions and unjustified health care costs may result. Earlier research shows that even off-label prescribed drugs (no distinction between ill- and wellfounded) sometimes induce more adverse drug reactions than drugs prescribed onlabel.1-3 One important motive for physicians to prescribe off-label is the fact that the effectiveness of drugs is described in clinical guidelines, guidebooks and/or (new) scientific literature. However, motives that are based on experimental tendencies do also occur, such as the idea that the drug might be effective because of the registered indications or the supposed working mechanism, as well as good experiences observed by the professionals involved.4 In 2005 the Dutch Medicines Evaluation Board and the Dutch Health Care Inspectorate stated that off-label prescribing should only be permitted if there is appropriate scientific evidence, that is, well-founded.5 This statement was taken over in the Dutch Medicines Act, which came into force in July 2007.

For several groups of drugs or specific patient populations, the occurrence of off-label prescribing has been studied. Fairly large frequencies have been found,

for example, $17 \%$ of prescriptions for hospitalized elderly6 and 32\% of prescriptions for patients with dermatological diseases.7 Other topics studied were for antipsychotics,8 pregnant women,9 children10,11 and drugs used in oncology.12 Two studies carried out in the Netherlands showed that the same magnitude can be expected in general practice: $11-72 \%$ for new introduced drugs and 21-58\% for antidepressants in children and adolescents.13-15 When off-label prescribing is studied, researchers do not very often make a distinction between well-founded and ill-founded off-label prescribing. Accordingly, we wanted to quantify the occurrence of ill-founded off-label prescribing for a broad range of drugs. Because $75-80 \%$ of all prescribed drugs in the Netherlands are prescribed by GPs, we wanted to focus on general practice. We wonder if GPs, being generalists, know the exact indications of all prescribed drugs. One important aspect here is the understanding that in the Netherlands, the GP acts as a gatekeeper to the health care system. All Dutch inhabitants are registered with a general practice and the GP is the first person consulted when health problems arise. Moreover, after a patient referral, a visit to an Accident and Emergency department, or after a hospital admission, the GP is informed about the medical findings (e.g. diagnosis and laboratory results) and interventions.

\section{METHODS}

Data

Data were used from the Netherlands Information Network of General Practice (LINH), an information network of a representative sample of general practices in the Netherlands.16We assessed the occurrence of illfounded prescribing in 2004. In order to examine the medical 
Gijsen, R., Jochemsen, H., Dijk, L. van, Caspers, P. Frequency of ill-founded off-label prescribing in Dutch general practice. Pharmacoepidemiology and Drug Safety: 2009, 18(1), 84-

context, we also used patients' medical information from 2003. In total, 78 general practices with a total patient population of 319843 persons were included in our analysis.

Participating GPs routinely register all patient contacts in electronic medical records.

Subjects of registration are diagnoses, prescriptions, and referrals to other health care professionals. Diagnoses are coded according to the ICPC-1,17 and drugs according to the ATC-classification.18 In 2004, an ICPC-code was assigned to almost $100 \%$ of all patient contacts, and to $72.4 \%$ of all prescriptions.

\section{Definitions}

Off-label prescribing was defined as 'a prescription for an indication different from the indications stated in the Dutch SPC'. Off-label prescribing due to age, dose, route of administration or contra-indications were not evaluated. Oncological indications were excluded,

since these were hardly ever prescribed by GPs. An offlabel combination was defined as a combination of a drug with an off-label indication for this specific drug.

An ill-founded off-label prescription was defined as an off-label prescription which is not recommended in pharmacotherapeutic handbooks or clinical practice guidelines.

\section{Relevant ill-founded off-label combinations}

In order to determine which combinations of drugs and off-label indications were suitable for study in general practice, we made an inventory of known off-label combinations described in international literature,

pharmacotherapeutic handbooks and Dutch clinical practice guidelines. Moreover, we asked innovative pharmaceutical companies, the Netherlands Pharmacovigilance Centre (LAREB), the Royal Dutch Pharmaceutical Society and the Dutch Association of Health Care Insurers to report cases of undesirable off-label use. From the inventory we made a selection of combinations of drugs and ill-founded off-label indications using the following criteria:

- the indication is not included in the Dutch SPC;

- off-label use for this indication is not recommended in pharmacotherapeutic handbooks (the 2005 editions of Dutch Physicians Desk Reference, the pharmacotherapeutic handbook of the Dutch pharmacists and the United States Pharmacopeia-Drug Information, Volume I);

- off-label use for this indication is not recommended in Dutch clinical practice guidelines, largely developed by the Dutch College of General Practitioners and the Dutch Institute of Health Care Improvement;

- the indication is likely to occur in general practice, since the expected overall prevalence of the indication in a general practice population is more than 1 per 1000 persons;

- the combination of drug and off-label indication can be operationalized using the International Classification for Primary Care (ICPC) and the Anatomical Therapeutic Chemical (ATC) classification.

The inventory resulted in 477 off-label combinations, of which 48 met the above criteria of illfounded off-label combinations (Table 1, columns 1 and 2).

\section{Analysis}

The drugs included in our analysis could be assigned to a maximum of two ATC-codes. For off-label indications,we sometimes had to use a wider range of ICPCcodes.

Borderline personality disorder, for example,does not have a unique ICPC-code. Therefore, it was classified as personality disorder-a broader definition (Table 1, columns 3 and 4). When such broader disease categories were used, we also verified that no other disease within that broader category was an approved indication for the examined drug (Table 1, column 5). 
Gijsen, R., Jochemsen, H., Dijk, L. van, Caspers, P. Frequency of ill-founded off-label prescribing in Dutch general practice. Pharmacoepidemiology and Drug Safety: 2009, 18(1), 84-

We selected all patients who had one of the 48 potentially ill-founded off-label combinations of drug and indication in 2004. For each selected patient, all medical information available in the database was examined for the years 2004 and 2003. This included diagnoses (including co-morbidity), referrals, reasons for referrals, other prescriptions and indications for other prescriptions. As such, we were able to review the character of the prescription in a broader context and to deselect prescriptions that were off-label at first sight,but after reviewing were not conclusively off-label.

There can be plausible explanations why a combination of a drug and indication at first sight seems to be off-label: (a) the disease for which the drug was given is present, but was not registered at the moment of prescription, (b) at the moment of prescription, the disease was not yet diagnosed and registered, but some time later it was, (c) at the moment of prescription, the GP registers the (off-label) chronic disease of the patient, instead of the (onlabel) complaint for which the drug is meant and (d) the GP makes a mistake when entering the codes in the electronic medical record.

Using the numbers before and after deselection, a range could be defined around the true number of illfounded off-label prescriptions. These were related to the total number of prescriptions of the drug concerned and the total number of prescriptions with the relevant indication. Data were analysed using SPSS for Windows, Rel. 12.0.1. (Chicago: SPSS Inc., 2003).

\section{RESULTS}

The database included 319843 patients, who received a total of 2678 off-label prescriptions for the selected 48 combinations of drugs and ill-founded off-label indications in 2004. After studying additional medical information on these patients, 487 prescriptions (18.2\%) were excluded because there was reason to assume that the prescription may not have been offlabel.

Most prescriptions were excluded because the patient received a different drug for one of the approved indications of the examined drug (8.1\%).

Consequently, 2191 prescriptions could be considered as convincingly ill-founded off-label.

Table 2, shows that, after excluding non-conclusive off-label prescriptions, only 25 of the examined 48 combinations of drugs and off-label indications were found in the database. We summarize the main results here. For 21 combinations, no prescriptions were found in the initial search (see Table 1). Four drugs had more than 100 off-label prescriptions. The proportions of illfounded off-label prescriptions among all prescriptions for a particular drug, varied from less than $1 \%$ for several drugs, to $26.7 \%$ for betahistine. For the COX-2 inhibitors celecoxib and etoricoxib, 16.3 and $12.5 \%$ respectively were prescribed for back symptoms in 2004. Olanzapine and risperidone were prescribed for three ill-founded offlabel indications: ADHD, aggression in children and adolescents and antisocial personality disorder. Of all prescriptions of olanzapine,5.1\% was prescribed off-label for these off-label indications, and of all prescriptions of risperidone, $10.0 \%$.

\section{DISCUSSION}

This study assessed the occurrence of ill-founded offlabel prescribing in the Netherlands by GPs. Fortyeight combinations of drugs and ill-founded off-label indications were included in this study. In a patient population of 319843 patients, 2191 prescriptions were found with one of these combinations. In these cases there is no evidence to justify a good balance between effectiveness and safety. Because no ICPCcode was assigned to $27.6 \%$ of all prescriptions, we do [table 1] not want to make an estimate of the frequency of illfounded off-label prescribing in the total practice population. Besides, our research concerned only a selection of all possible ill-founded off-label combinations.

The number of 2191 prescriptions (as above) suggests that the occurrence of ill-founded off-label prescribing by general practitioners in the Netherlands is limited, with a few 
Gijsen, R., Jochemsen, H., Dijk, L. van, Caspers, P. Frequency of ill-founded off-label prescribing in Dutch general practice. Pharmacoepidemiology and Drug Safety: 2009, 18(1), 84-

exceptions. In other studies, researchers found percentages of 20 or more (ill- and wellfounded together).6-15 However, some remarks should be made here. As previously mentioned, we made a selection of combinations of drugs and illfounded off-label indications that can be expected in a general practice database and, as such, this study does not comprise the full range of ill-founded off-label combinations. The possibilities for offlabel prescribing are almost inexhaustible. Moreover, the current study only measured indication-related off-label use.

Off-label use related to age, dosage, duration of time, route of administration and presence of contraindications were not examined.

Data came from a large, nationwide general practice network. Information about patient contacts is registered in an electronic information system that mainly takes place during patient contacts. Because a large majority of the general practices in the Netherlands have a computerized patient registration system (Electronic Patient Record), GPs who participate in the LINH network should not be very different from GPs who do not participate in LINH. In addition, research showed that there were only small differences in medical practice between GPs participating in LINH and non-participating GPs.19 In contrast to previous studies, which studied all the prescriptions outside the SPC, this study focused especially on off-label indications that are not documented as well founded. In addition, we used all patients' medical information available in the database, to control for limitations in the database and mistakes that could have been made by GPs when adding information at any point in time. As a result, we demonstrated that for $81.8 \%$ of all potentially ill-founded off-label prescriptions, the drug was actually prescribed for an illfounded off-label indication. For the other $18.2 \%$, the prescription might have been prescribed on-label. The only other study that explicitly looked at ill-founded off-label prescribing was performed in the USA among office-based physicians. 20 The authors found that about $15 \%$ of all prescriptions was illfounded off-label. For specific drugs, the percentages were higher than in our study. This may partly be due to the fact that they applied different methods, used data from 2001, had a different patient population (including patients treated [table 2] by physicians working in ambulatory secondary care services) and was performed in a country with a different health care system to the Netherlands.

The combinations of drugs and ill-founded off-label indications observed most frequently were betahistine for dizziness (not Me'nie`re), celecoxib for back symptoms, etoricoxib for back symptoms and amitriptyline for headache (not migraine). For each of the studied diagnoses, the percentage of off-label prescriptions of all prescriptions was $<6 \%$. The only exception was dizziness, for which betahistine was prescribed in $32.5 \%$ of all prescriptions. This drug is strictly approved for 'the syndrome of Me'nie `re'. It is hard to distinguish between the various forms of dizziness.21 The Dutch Physicians Desk Reference states that before prescribing a drug for dizziness, the physician needs to reach a precise diagnosis and to prescribe approved drugs only.22 Apparently, many GPs do not know the strict indication for betahistine or they doubt the diagnosis that they made. The latter is confirmed by the fact that over 300 (24.4\%) of the offlabel prescriptions for betahistine were excluded by applying the selection criteria. These are the prescriptions of patients who received a diagnosis both for Ménie 're and dizziness. Betahistine does not have severe adverse drug reactions, aside from increased risk of respiratory problems in asthma patients. Drugs that do have more serious adverse reactions are antipsychotic drugs, including the atypical antipsychotic drugs olanzapine and risperidone.23-24 Of all prescriptions of olanzapine, 5.1\% was prescribed offlabel for personality disorders or behaviour problems, and of all prescriptions of risperidone, $10.0 \%$ was prescribed off-label for these indications. In other studies higher frequencies were found.25-26 In the Netherlands, COX-2 inhibitors are known for their frequent off-label prescribing.27,28 The reasons why GPs prescribe COX-2 inhibitors off-label are - the supposed smaller amount of adverse effects (stomach problems), user-friendliness, and the continuation of earlier prescriptions by the medical specialist. Besides, GPs think the 
Gijsen, R., Jochemsen, H., Dijk, L. van, Caspers, P. Frequency of ill-founded off-label prescribing in Dutch general practice. Pharmacoepidemiology and Drug Safety: 2009, 18(1), 84-

drug is beneficial for a broader range of indications than those for which it is in fact registered.

28 Some years ago, concern arose about the safety of COX-2 inhibitors, as their use may increase the risk of cardiovascular events, especially myocardial infarctions.

29 Based on this example of recently introduced, potentially hazardous drugs, we think it is worthwhile to assess the frequency in general practice on a routine basis.

One final observation is that although different studies have shown drugs off-label prescribed for obesity,30 we did not find these combinations, apart from fluoxetine and obesity (only four prescriptions in 2004).We are therefore inclined to conclude that Dutch GPs do not prescribe ill-founded drugs for obesity, although we cannot rule out that when a drug is given for obesity, GPs register a code for a chronic disease that is closely related to obesity (like diabetic mellitus, hypertension and heart failure), instead of obesity.

No successful treatment is available for many of the examined off-label indications. Kos et al.31 showed that dissatisfaction with available drug therapy is one of the incentives for offlabel use. Examples here are chronic headache, dizziness, obesity and alopecia androgenatica in women. Research on new therapies or research on off-label therapies for such indications should be stimulated.

\section{CONCLUSION}

This study shows that ill-founded off-label prescribing in Dutch general practice is limited to 48 relevant combinations of drugs and off-label indications. An important exception to this rule is betahistine for dizziness. We know from other studies that GPs lack knowledge about the on- or off-label status of a drug at the moment of prescribing. Supporting GPs by the inclusion of a reporting system in their electronic patient registration, that gives a message if an illfounded drug is prescribed, can prevent them from prescribing drugs for undesired off-label indications.

Other exceptions are COX-2 inhibitors, prescribed for back symptoms. Especially for recently introduced drugs, registration networks like LINH are highly suitable for monitoring ill-founded off-label prescribing on a day-to-day basis. For many of the examined off-label indications, no good, successful treatment is available. Therefore, research on therapies for such indications (including off-label therapies) should be stimulated.

\section{ACKNOWLEDGEMENTS}

This study was carried out as part of a broader programme on off-label prescribing, commissioned and subsidized by the Dutch Health Care Inspectorate (coordination by N.C. Kijlstra, MSc).

\section{REFERENCES}

1. Jonville-Béra AP, Béra F, Autret-Leca E. Are incorrectly used drugs more frequently involved in adverse drug reactions? A prospective study. Eur J Clin Pharmacol 2005; 61: 231-236.

2. Choonara I, Conroy S. Unlicensed and off-label drug use in children: implications for safety. Drug Saf 2002; 25: 1-5.

3. European Medicines Agency. Evidence of harm from off label or unlicensedmedicines in children. EMEA/11207/04. London, 26 October 2004; http://www.emea.europa.eu/pdfs/human/paediatrics/12632704en. pdf [Accessed 25 May 2008].

4. Jochemsen H, Gijsen R, Caspers P. Off-label voorschrijven: medisch handelen en motieven van huisartsen. [Off-label prescribing: clinical practice and motives of general practitioners. Huisarts Wet 2007; 50: 193-197.

5. Medicines Evaluation Board. Verantwoord off-label voorschrijven mag. [Medicines Evaluation Board and Health Care Inspectorate are not against good off-label use, but are against wrong off-label use.] 18 February 2005; http://www.cbg-meb.nl/CBG/nl/about- 
Gijsen, R., Jochemsen, H., Dijk, L. van, Caspers, P. Frequency of ill-founded off-label prescribing in Dutch general practice. Pharmacoepidemiology and Drug Safety: 2009, 18(1), 84-

cbg/actueel/ 2005-02-18-CBGpenpIGZpverantwoordpoff-labelpvoorschrijvenp mag/default.htm [in Dutch; accessed 20 July 2008]. Later taken over at http://www.cbgmeb.nl/CBG/en/human-medicines/medicinalpproducts/

Off-labelpuse/What-is-correct-off-label-use/default.htm [in English; accessed 20 July 2008].

6. Hames A, Wynne HA. Unlicensed and off-label drug use in elderly people. Age Ageing 2001; 6: 530-531.

7. Sugarman JH, Fleischer $A B$, Feldman SR. Off-label prescribing in the treatment of dermatological disease. J Am Acad Dermatol 2002; 47: 217-223.

8. Hodgson R, Belgamwar R. Off-label prescribing by psychiatrists. Psychiatr Bull 2006; 30 : $55-57$.

9. Rayburn WF, Turnbull GL. Off-label drug prescribing on a state university obstetric service. J Reprod Med 1995; 40: 186-188.

10. Schirm E, Tobi H, de Jong-van den Berg LTW. Risk factors for unlicensed and off-label drug use in children outside the hospital. Pediatrics 2003; 111: 291-295.

11. 't Jong GW, van der Linden PD, Bakker EM, van der Lely N, Eland IA, Stricker BH, van den Anker JN. Unlicensed and off-label drug use in a paediatric ward of a general hospital in the Netherlands. Eur J Clin Pharmacol 2002; 58: 293-297.

12. Poole SG, Dooley MJ. Off-label prescribing in oncology. Support Care Cancer 2004; 12 : 302-305.

13. Van Dijk L, Florentinus S, de Jong A, Velthove K, Heerdink R, Kallewaard M. Het voorschrijven van nieuwe geneesmiddelen in de huisartspraktijk: voorschrijfvolume en offlabel voorschrijven. [Prescribing of new drugs in general practice: volume and off-label prescribing.] Utrecht: NIVEL, 2003.

14. Van Dijk L, De Jong A, Florentinus S, Verheij R. Off-label voorschrijven in de huisartspraktijk, therapeutisch probleem of academisch probleem? [Off-label prescribing in the general practice, therapeutic problem or academic problem?]. Pharm Weekbl 2004; 139: 902-905.

15. Volkers AC, Heerdink ER, van Dijk L. Antidepressant use and off-label prescribing in children and adolescents in Dutch general practice (2001-2005). Pharmacoepidemiol Drug Saf 2007; 16: 1054-1062.

16. Verheij RA, Jabaaij L, Abrahamse $\mathrm{H}$, van den Hoogen $\mathrm{H}$, Braspenning J, van Althuis $\mathrm{T}$. Landelijk Informatienetwerk Huisartsenzorg. Feiten en cijfers over huisartsenzorg in Nederland. [Netherlands Information Network of General Practice. Facts and figures about primary care in the Netherlands.] Utrecht/Nijmegen: LINH/WOK: http://www.linh.nl, November 2005.

17. Lamberts H, Wood M (eds). ICPC. International Classification of Primary Care. Oxford University Press: Oxford, 1987.

18. WHO Collaborating Centre for Drug Statistics Methodoloy. http:// www.whocc.no/atcddd/ [Accessed November 2005].

19. Westert GP, Hoonhout LHF, de Bakker DH, van den Hoogen HJM, Schellevis FG. Huisartsen met en zonder elektronisch medisch dossier: weinig verschil in medisch handelen. [General practitioners with and without electronic computerized patient registration: little difference in medical practice.] Huisarts Wet 2002; 45: 58-62.

20. Radley DC, Finkelstein SN, Stafford RS. Off-label prescribing among office-based physicians. Arch Intern Med 2006; 166: 1021-1026.

21. Verheij AAA, vanWeert HCPM, Lubbers WJ, Van Sluisveld ILL, Saes GAF, Eizenga WH, Boukes FS, van Lieshout J. NHG-Standaard duizeligheid [Clinical practice guideline dizziness]. Utrecht: Dutch College of General Practitioners, 2002.Website: http://nhg.artsennet.nl [Accessed July 2007].

22. Health Care Insurance Board (CVZ). Genees- en hulpmiddelen Informatie Project. [The Drug Information System.] Diemen: CVZ, 2007. Website http://www.gipdatabank.nl/ [Accessed July 2007].

23. Correll CU, Penzner JB, Parikh UH, Mughal T, Javed T, Carbon M, Malhotra AK. Recognizing and monitoring adverse events of secondgeneration antipsychotics in children and adolescents. Child Adolesc Psychiatr Clin N Am 2006; 15: 177-206.

24. Fedorowicz VJ, Fombonne E. Metabolic side effects of atypical antipsychotics in children: a literature review. J Psychopharmacol 2005; 19: 533-550. 
Gijsen, R., Jochemsen, H., Dijk, L. van, Caspers, P. Frequency of ill-founded off-label prescribing in Dutch general practice. Pharmacoepidemiology and Drug Safety: 2009, 18(1), 84-

25. Rijcken CAW, Boelema GJ, Slooff CJ, Beuger PJ, Tanja TA, de Jong- van den Berg LTW. Off-label use of antipsychotics in the community pharmacy: the sex differences. Pharmacopsychiatry 2003; 36: 187-191.

26. Rawal PH, Lyons JS, Maclntyre JC 2nd, Hunter JC. Regional variation and clinical indicators of antipsychotic use in residential treatment: a four-state comparison. J Behav Health Serv Res 2004; 31: 178-188.

27. Florentinus SR, van Dijk L, Velthove KJ, Heerdink ER, Groenewegen PP, Leufkens HGM. Off-label use of the new drug rofecoxib. In: Florentinus SR. New drugs in general practices: prescribing patterns and external influences. Thesis, Utrecht, Utrecht University, 2006.

28. Davidse W, Somai D, Perenboom R, Verheij R, de Bakker D, van Dijk L. Doelmatig voorschrijven van nieuwe geneesmiddelen; off label voorschrijven van COX-2 remmers als casus. [Efficient prescribing of new drugs; off-label prescribing of COX-2 inhibitors as a case study.] Leiden, TNO Kwaliteit van Leven, 2006.

29. Zarraga IGE, Schwarz ER. Coxibs and heart disease. What we have learned and what else we need to know. J Am Coll Cardiol 2007; 49: 1-14.

30. Walker S, Poston C, Haddock CK, Dill LP, Thayer B, Foreyt JP. Lifestyle treatments in randomized clinical trials of pharmacotherapies for obesity. Obes Res 2001; 9: 552-563.

31. Kos M, Wertheimer Al, Mrhar A. Satisfaction with pharmacotherapy for approved and offlabel indications-a Delphi study. Ann Pharmacother 2005; 39: 649-654.

\section{TABLES AND ANNEXE}

\section{KEY POINTS}

- The examination of 48 combinations of drugs and ill-founded off-label indications in Dutch general practice, showed that combinations with betahistine, celecoxib and etoricoxib occurred most frequently. Overall, on the basis of these 48 examined ill-founded off-label combinations, it appears that off-label prescribing of medication not recommended in clinical practice guidelines or handbooks, is limited in Dutch general practice.

- In evaluating the on- or off-label status of a prescription, it is useful to examine all available patient information, for example, co-medication and co-morbidity, in order to decide whether an off-label prescription is conclusively off-label. In this study, over 18 per cent of all prescriptions of the 48 combinations of drugs and ill-founded offlabel indications examined was re-evaluated as on-label, upon examination of the patient's medical history.

- The prevalence of off-label prescribing can be assessed in general practice information networks. Such information networks are useful to monitor ill-founded off-label prescriptions on a day-to-day basis, especially for recently introduced drugs. 
Table 1. Overview of the examined combinations of drugs and off-label indications, ICPC-1 codes, descriptions of the applied off-label indications and codes of the approved on-label indications in

\begin{tabular}{|c|c|c|c|c|}
\hline Drugs & Off-label indications & $\begin{array}{l}\text { Applied off-label indication } \\
\text { codes (ICPC-codes) }\end{array}$ & ICPC description of applied off-label codes & $\begin{array}{l}\text { ICPC-codes of approved } \\
\text { on-label indications }\end{array}$ \\
\hline \multicolumn{5}{|c|}{ Combinations for which prescriptions were found in LINH } \\
\hline Cimetidine & Warts in children & $\mathrm{S} 03(\mathrm{age}<25)$ & Warts in children & D84, D85, D86, D87 \\
\hline Hydroxyethylrutosides & $\begin{array}{l}\text { Diabetes mellitus (incl. diabetic } \\
\text { microangiopathy) }\end{array}$ & T90 & Diabetes mellitus & K06, K94, K95 \\
\hline Verapamil & Prophylaxis of migraine & N89 & Migraine & $\begin{array}{l}\mathrm{K} 74, \mathrm{~K} 75, \mathrm{~K} 76, \mathrm{~K} 78, \mathrm{~K} 79, \\
\mathrm{~K} 85, \mathrm{~K} 86, \mathrm{~K} 87\end{array}$ \\
\hline Lisinopril & Prophylaxis of migraine & N89 & Migraine & K85, K86, K75, K77, T90 \\
\hline Finasteride & Alopecia androgenetica in women & S23 (females) & Hair loss/alopecia (females) & $\begin{array}{l}\text { No selection criteria used since } \\
\text { the drug is off-label for females }\end{array}$ \\
\hline Estrogens & Stress incontinence & U04 & Urine-incontinence (not enuresis) & $\begin{array}{l}\text { Wide range of indications, not } \\
\text { exactly covered: Chapter W, } \\
\text { Chapter X, L95 }\end{array}$ \\
\hline Oxybutynin & Gastro-intestinal disorders (spasms) & Chapter D & Tractus digestivus & U02, U04, U05, U13 \\
\hline Desmopressin & Nocturia due to prostate complaints & $\begin{array}{l}\text { Chapter U, Y06, Y } 85 \\
\text { age } \geq 25, \text { male }\end{array}$ & $\begin{array}{l}\text { Urinary tract (not other symptoms/complaints } \\
\text { urine), symptoms/complaints of prostate, benign } \\
\text { prostate hypertrophy }\end{array}$ & T01, T99, P12 (age < 25) \\
\hline Meloxicam & Neuropathic pain & Chapter $\mathrm{N}$ & Nervous system & L84, L88, L89, L90, L91 \\
\hline Celecoxib & Backache (no rheumatoid arthritis) & L02, L03, L86 & $\begin{array}{l}\text { Back symptoms/complaints, low-backache with } \\
\text { or without radiation }\end{array}$ & L84, L88, L89, L90, L91 \\
\hline Etoricoxib & Backache (no rheumatoid arthritis) & L02, L03, 86 & $\begin{array}{l}\text { Back symptoms/complaints, low-backache with } \\
\text { or without radiation }\end{array}$ & L84, L88, L89, L90, L91, T92 \\
\hline Methysergide & Tension headache & N02 & Tension headache & $\mathrm{N} 89, \mathrm{~N} 90, \mathrm{D} 11$ \\
\hline Valproate sodium & Schizophrenia & P72 & Schizophrenia & N88 \\
\hline Carbamazepine & Gambling addiction & P80 & Personality-/character disorder & $\begin{array}{l}\text { N86, N88, N92, P15, P73, } \\
\text { T01, T99, U02 }\end{array}$ \\
\hline Lamotrigine & Borderline syndrome & P80 & Personality/character disorder & N89 \\
\hline Topiramate & Bipolar disorder & Chapter P & Mental problems & N88, N89 \\
\hline Gabapentin & Bipolar disorder & Chapter P & Mental problems & $\mathrm{N} 88^{\mathrm{a}}$ \\
\hline Gabapentin & Restless legs syndrome & N04 & Restless legs & $\mathrm{N} 88^{\mathrm{a}}$ \\
\hline Olanzapine & $\mathrm{ADHD}^{\dagger} \mathrm{CH}$ & P21 & Overactive child/hyperkinetic syndrome & P72, P73 \\
\hline Olanzapine & Antisocial personality disorder & P80 & Personality/character disorder & P72, P73 \\
\hline Risperidone & $\mathrm{ADHD}^{+}$ & P21 & Overactive child/hyperkinetic syndrome & P70, P72, P73 \\
\hline Risperidone & Aggression in children and adolescents ${ }^{\dagger}$ & $\mathrm{P} 22, \mathrm{P} 23 ;$ age $\leq 30$ & Other concerns behaviour child or adolescent & P70, P72, P73 \\
\hline Risperidone & $\begin{array}{l}\text { Antisocial personality disorder } \\
\text { S }\end{array}$ & P80 & Personality/character disorder & P70, P72, P73 \\
\hline Amitriptyline & Chronic headache (not migraine) & N01 & $\begin{array}{l}\text { Headache (not tension headache, migraine or } \\
\text { symptoms/complaints sinuses) }\end{array}$ & $\mathrm{P} 12, \mathrm{P} 76$ \\
\hline Fluoxetine & Obesity & T82, T83 & Obesity $(\mathrm{QI}>30)$ or overweight $(\mathrm{QI} \leq 30)$ & P76, P79, T06 \\
\hline Naltrexone & Gambling addiction & P80 & Personality/character disorder & $\mathrm{P} 15, \mathrm{~S} 02$ \\
\hline Betahistine & Dizziness (not Ménière) & N17 & Vertigo/dizziness (not Ménière) & $\mathrm{H} 82$ \\
\hline \multicolumn{5}{|c|}{ Combinations for which no prescriptions were found in LINH } \\
\hline Cimetidine & Obesity & T82, T83 & Obesity $(\mathrm{QI}>30)$ or overweight $(\mathrm{QI} \leq 30)$ & D03, D84-86 \\
\hline Metformin & Obesity & T82, T83 & Obesity $(\mathrm{QI}>30)$ or overweight $(\mathrm{QI} \leq 30)$ & T90 \\
\hline Acarbose & Obesity & $\mathrm{T} 82, \mathrm{~T} 83$ & Obesity $(\mathrm{QI}>30)$ or overweight $(\mathrm{QI} \leq 30)$ & T90 \\
\hline Topiramate & Obesity & T82, T83 & Obesity $(\mathrm{QI}>30)$ or overweight $(\mathrm{QI} \leq 30)$ & N88, N89 \\
\hline Bromocriptine & Obesity & T82, T83 & Obesity $(\mathrm{QI}>30)$ or overweight $(\mathrm{QI} \leq 30)$ & $\begin{array}{l}\text { N87, W19, X21, Y7, Y10, } \\
\text { Y16, T29, T73, T99 }\end{array}$ \\
\hline Fluvoxamine & Obesity & $\mathrm{T} 82, \mathrm{~T} 83$ & Obesity $(\mathrm{QI}>30)$ or overweight $(\mathrm{QI} \leq 30)$ & P76, P79 \\
\hline Sertraline & Obesity & $\mathrm{T} 82, \mathrm{~T} 83$ & Obesity $(\mathrm{QI}>30)$ or overweight $(\mathrm{QI} \leq 30)$ & P74, P76 \\
\hline
\end{tabular}

Obesity $(\mathrm{QI}>30)$ or overweight $(\mathrm{QI} \leq 30)$
Obesity $(\mathrm{QI}>30)$ or overweight $(\mathrm{QI} \leq 30)$ 


\begin{tabular}{|c|c|c|c|c|}
\hline Drugs & Off-label indications & $\begin{array}{l}\text { Applied off-label indication } \\
\text { codes (ICPC-codes) }\end{array}$ & ICPC description of applied off-label codes & $\begin{array}{l}\text { ICPC-codes of approved } \\
\text { on-label indications }\end{array}$ \\
\hline Pentoxifylline & Diabetic neuropathy & T90 AND N94 & $\begin{array}{l}\text { Diabetes mellitus AND other peripheral } \\
\text { neuritis/neuropathy }\end{array}$ & K92 \\
\hline Buspirone & (Diabetic) neuropathy & N94 & Other peripheral neuritis/neuropathy & P01, P74 \\
\hline Atenolol & Chronic weariness syndrome after Pfeiffer & A04 AND A75 & $\begin{array}{l}\text { Weakness/tiredness AND infectious } \\
\text { mononucleosis }\end{array}$ & $\begin{array}{l}\text { K04, K78-80, K74-K76, } \\
\text { K85, K86 }\end{array}$ \\
\hline Clonidine & Nicotine addiction & P17 & Tobacco abuse & N89, X11 \\
\hline Carbamazepine & Migraine & N89 & Migraine & $\begin{array}{l}\text { N86, N88, N92, P15, P73, } \\
\text { T01, T99, U02 }\end{array}$ \\
\hline Gabapentin & Migraine & N89 & Migraine & N88* \\
\hline Gabapentin & Migraine & N89 & Migraine & N88* \\
\hline Gabapentin & Withdrawal signs for alcohol or drugs & P15, P19 & Chronic alcohol abuse or drug abuse & $\mathrm{N} 88^{*}$ \\
\hline Olanzapine & Aggression in children and adolescents ${ }^{\dagger}$ & $\mathrm{P} 22, \mathrm{P} 23 ;$ age $\leq 30$ & Other concerns behaviour child or adolescent & P72, P73 \\
\hline Olanzapine & Obsessive disorder & P79 & Other neurosis & P72, P73 \\
\hline Quetiapine & Obsessive disorder & P79 & Other neurosis & P72, P73 \\
\hline Imipramine & Stress incontinence & U04 & Urine-incontinence & P76, P12 \\
\hline Montelukast & Urticaria & S98 & Urticaria & R96, R97 \\
\hline Cyproheptadine & Anorexia nervosa & T06 & Anorexia nervosa/bulimia & $\begin{array}{l}\text { A12, A85, R97, S12, S87, } \\
\text { S88, S98 }\end{array}$ \\
\hline
\end{tabular}

${ }^{*}$ By now, also approved for N94, S70 and T90.

${ }^{\dagger} \mathrm{By}$ now, also included in the guideline on ADHD for children and adolescents, in case of behaviour problems and aggression. 
Table 2. Quantification of the off-label prescriptions, practice population of 338118 persons

\begin{tabular}{|c|c|c|c|c|c|c|}
\hline Drugs & Applied off-label indications & $\begin{array}{l}\text { Number of } \\
\text { off-label } \\
\text { prescriptions }\end{array}$ & $\begin{array}{c}\text { Number of } \\
\text { off-label } \\
\text { prescriptions } \\
\text { deselected } \\
\text { (not conclusively } \\
\text { off-label) }\end{array}$ & $\begin{array}{c}\text { Number of } \\
\text { conclusively } \\
\text { off-label } \\
\text { prescriptions }\end{array}$ & $\begin{array}{l}\text { Percentage } \\
\text { off-label } \\
\text { prescriptions } \\
\text { with regard } \\
\text { to the total } \\
\text { number of } \\
\text { prescriptions } \\
\text { of the drug } \\
\text { concerned }\end{array}$ & $\begin{array}{c}\text { Percentage } \\
\text { off-label } \\
\text { prescription } \\
\text { with regard } \\
\text { to the total } \\
\text { number of } \\
\text { prescription } \\
\text { with the } \\
\text { indication } \\
\text { concerned }\end{array}$ \\
\hline Cimetidine & Warts in children & 3 & 0 & 3 & 0.3 & 0.4 \\
\hline Hydroxyethyl-rutosides & Diabetes mellitus (incl. diabetic microangiopathy) & 3 & 2 & 1 & 0.5 & 0.002 \\
\hline Verapamil & Migraine & 22 & 12 & 10 & 0.5 & 0.1 \\
\hline Lisinopril & Migraine & 7 & 4 & 3 & 0.1 & 0.03 \\
\hline Finasteride & Alopecia androgenetica in women & 10 & 0 & 10 & 1.1 & 5.2 \\
\hline Estrogens & Urine-incontinence & 59 & 39 & 20 & 0.5 & 0.7 \\
\hline Oxybutynin & Tractus digestivus & 20 & 13 & 7 & 0.9 & 0.01 \\
\hline Desmopressin & Urinary tract (incl. nocturia due to prostate complaints) & 20 & 0 & 20 & 2.8 & 0.2 \\
\hline Meloxicam & Nervous system (incl. neuropathic pain) & 46 & 3 & 43 & 1.8 & 0.1 \\
\hline Celecoxib & Back symptoms & 399 & 19 & 380 & 16.3 & 1.5 \\
\hline Etoricoxib & Back symptoms & 274 & 24 & 250 & 12.5 & 1.0 \\
\hline Methysergide & Tension headache & 2 & 0 & 2 & 15.4 & 0.1 \\
\hline Carbamazepine & Personality disorder (incl. gambling addiction) & 5 & 0 & 5 & 0.3 & 0.3 \\
\hline Valproate sodium & Schizophrenia & 11 & 0 & 11 & 0.5 & 1.1 \\
\hline Lamotrigine & Personality disorder (incl. borderline syndrome) & 1 & 1 & 0 & 0.0 & 0.0 \\
\hline Topiramate & Mental problems (including bipolar disorder) & 1 & 1 & 0 & 0.0 & 0.0 \\
\hline Gabapentin & Mental problems (including bipolar disorder) & 40 & 0 & 40 & 3.4 & 0.03 \\
\hline Gabapentin & Restless legs & 19 & 0 & 19 & 1.6 & 1.5 \\
\hline Olanzapine & Overactive child (incl. ADHD) & 2 & 0 & 2 & 0.1 & 0.2 \\
\hline Olanzapine* & Personality disorder (incl. antisocial) & 76 & 6 & 70 & 5.0 & 3.7 \\
\hline Risperidone & Overactive child (incl. ADHD) & 49 & 1 & 48 & 3.7 & 4.6 \\
\hline Risperidone & Other concerns behaviour child and adolescent (incl. aggression) & 23 & 0 & 23 & 1.8 & 7.3 \\
\hline Risperidone & Personality disorder (incl. antisocial) & 57 & 0 & 57 & 4.4 & 2.9 \\
\hline Amitriptyline & Headache (not migraine) & 260 & 46 & 214 & 3.0 & 4.3 \\
\hline Fluoxetine & Obesity/overweight & 14 & 10 & 4 & 0.1 & 0.8 \\
\hline Naltrexone & Personality disorder (incl. gambling addiction) & 3 & 0 & 3 & 5.5 & 0.2 \\
\hline Betahistine & Dizziness (not Ménière) & 1252 & 306 & 946 & 26.7 & 32.5 \\
\hline
\end{tabular}

*One outlier with 103 prescriptions of olanzapine was excluded. 